\title{
Targeted co-delivery of protein and drug to a tumor in vivo by sophisticated RGD-modified lipid- calcium carbonate nanoparticles
}

Jian Qing Peng ${ }^{\mathrm{a}, \mathrm{b}}$, Shintaro Fumoto ${ }^{\mathrm{a},}$, Tadaharu Suga ${ }^{\mathrm{a}}$, Hirotaka Miyamoto ${ }^{\mathrm{a}}$, Naotaka Kuroda ${ }^{\mathrm{a}}$, Shigeru Kawakami ${ }^{\text {a }}$, Koyo Nishida ${ }^{\text {a }}$

${ }^{a}$ Graduate School of Biomedical Sciences, Nagasaki University, Nagasaki 852-8501, Japan

b State Key Laboratory of Functions and Applications of Medicinal Plants, Guizhou Medical University, Guiyang 550014, China

* Corresponding author, Graduate School of Biomedical Sciences, Nagasaki University, 1-7-1 Sakamoto, Nagasaki 852-8501, Japan.

E-mail address: sfumoto@nagasaki-u.ac.jp (S. Fumoto).

TEL: +81-95-819-8568

FAX: +81-95-819-8567 


\section{ABSTRACT}

Synchronized bio-distribution of combination therapies has several merits such as synergistic effects and reduced side-effects. Co-delivery of a protein and small molecule drug using a single nanocarrier is challenging because they possess totally different characteristics. Herein, we report the development of sophisticated nanoparticles composed of lipids, calcium carbonate and RGD peptide ligands for the co-delivery of a protein and small molecule drug combination via a simple preparation method. A 'one-step' ethanol injection method was employed to prepare the highly organized nanoparticles. The nanoparticles exhibited a spherical shape with ca. $130 \mathrm{~nm}$ diameter, and clearly had an integrated lipid layer covering the periphery. As a ligand, an RGDmodified lipid was post-inserted into the nanoparticles, which was important to overcome the 'PEG dilemma'. The $\mathrm{pH}$-sensitivity of the targeted nanoparticles contributed to the efficient intracellular co-delivery of a protein and drug combination in Colon26 tumor cells, and noticeably improved their accumulation in the tumor region of xenograft mice. Synchronized bio-distribution of the protein and drug was achieved, which was the foundation for the synergistic effects of the combination. The targeting capability of the nanoparticles along with their $\mathrm{pH}$-sensitive drug release and the synchronized bio-distribution of their cargos led to the significant antitumor activity of the SOD and paclitaxel combination in mice. This study provides novel information for the design and preparation of functionalized nanoparticles for the delivery of a protein/drug combination in vivo.

Keywords: Superoxide dismutase, paclitaxel, RGD peptide, calcium carbonate, lipid nanoparticles 


\section{Introduction}

Combination therapies have been widely used as clinical treatments for many complex refractory diseases $[1,2]$. Combination therapies such as chemotherapeutic mixtures, nucleic acid-based gene therapies and bio-macromolecule-assisted strategies have shown to improve the therapeutic outcomes, ameliorate side effects and overcome multi-drug resistance in cancer treatments [3-5]. Despite the potential of improved clinical treatments from combination therapies, the lack of proper drug delivery systems may not guarantee spatially and temporally synchronized bio-distribution in vivo.

Currently, an increasing number of therapeutic proteins (such as insulin, monoclonal antibodies, and chimeric proteins) are used in clinical treatments [6]. However, only a few protein/small molecule drug combinations acting on multiple targets have been developed as potential therapies. Compared with small molecule drugs, proteins possess specific folded threedimensional structures that make it challenging to maintain their activity during in vivo delivery. Nanocarriers can be used to protect proteins from degradation and denaturation, and prolong their systemic circulation time [7]. In theory, therapeutic proteins can act both outside and inside of cells. For the development of protein/drug combinations, co-delivery systems are generally prepared using drug-encapsulated nanoparticles with proteins inserted on the periphery so they can act on the cell surface. For example, a membrane-associated cytokine TRAIL (tumor necrosis factor-related apoptosis-inducing ligand) was attached outside of doxorubicin-loaded graphene nanoparticles [8]. Monoclonal antibodies are widely used in such combinations as both therapeutic units and targeting moieties by conjugation to the nanoparticles $[9,10]$. However, single carrier nanoparticles encapsulating a drug/protein combination where both components function in the cytosol has been rarely reported to date, while there are several examples of 
sequential treatments including apoptin proteins/dacarbazine [11], apoptin

proteins/paclitaxel/etoposide [12], and caspase-3/flavopiridol [13] combinations. Because of the major differences in the characteristics between biomacromolecules and small molecules, including their molecular weight, water solubility and stability in solvents, it is more challenging to co-encapsulate protein/drug combinations in single nanoparticles than small molecule drug combinations.

Superoxide dismutase (SOD) is an antioxidant enzyme that catalyzes the reaction from superoxide anion $\left(\mathrm{O}_{2}^{-}\right)$to hydrogen peroxide $\left(\mathrm{H}_{2} \mathrm{O}_{2}\right)$ thereby regulating the levels of reactive oxygen species (ROS) [14]. Tumor cells with hyper-metabolism might generate abundant ROS from the mitochondria and endoplasmic reticulum [15]. Under certain circumstances, the elevated ROS levels promote cell growth. ROS can also induce apoptosis via proapoptotic signal molecules [16]. Alexis et al. found that the excessive $\mathrm{H}_{2} \mathrm{O}_{2}$ in tumor cells with a high level of ROS, such as Colon26 and Hepa 1-6 liver tumor cells, would surpass the concentration range of ROS normally associated with proliferation and result in the inhibition of cell growth [17]. They evaluated the growth inhibition effects of several combinations of SOD mimics and chemotherapeutic drugs. Among them, SOD mimics and paclitaxel (PTX) combinations showed a remarkable inhibition effect on the proliferation of Colon26 tumor cells. Therefore, we formulated nanoparticles with a SOD/PTX therapeutic combination to study the inhibition of colon tumor growth.

Electrostatic and hydrophobic interactions have been verified to contribute to the formation of protein/lipid nanocomplexes from a structure-function relationship study [18]. Generally, the encapsulation of hydrophobic drugs into such lipid systems is based on hydrophobic interactions and hydrogen bonding among drugs, lipids and proteins. Therefore, we 
hypothesized that a mixture of a cationic lipid and a neutral lipid at a certain ratio would simultaneously interact with lipophilic drugs and proteins, and subsequently form the nanoparticle backbone.

To promote the endosomal escape of encapsulated cargos, calcium carbonate $\left(\mathrm{CaCO}_{3}\right)$ is widely used in nanoparticles for the delivery of drugs and genes [19]. Due to its inherent $\mathrm{pH}$ sensitivity, $\mathrm{CaCO}_{3}$ can be destroyed in the acidic environment of the lysosome and promote drug release. Polyelectrolytes were reported to act as the template for the formation of $\mathrm{CaCO}_{3}$ via electrostatic interactions with $\mathrm{Ca}^{2+}$ ions [20]. In a previous study, we formulated a lipid-based ternary system for a doxorubicin/curcumin combination therapy with a 'one-step' preparation method based on ethanol injection [21]. In the nanoparticles, $\mathrm{CaCO}_{3}$ was encapsulated with the help of polyacrylic acid, a polyelectrolyte, which served as a backbone. Because proteins are a type of polyelectrolyte, they possess abundant anionic moieties, and thus in this study, the nanocarrier was further improved to allow encapsulation of protein/drug combinations and $\mathrm{CaCO}_{3}$. If proteins are dissolved in the water phase, they are expected to form complexes, not spherical core-shell type nanoparticles. Therefore, to encapsulate proteins in the nanoparticles, it is necessary to add the proteins to the ethanol phase. However, as proteins generally aggregate in ethanol, optimization of the system is required to stably disperse the proteins in the ethanol phase.

To deliver nanoparticles to specific tissues and cells, ligand modification is a rational strategy. Recently, we have reported high functionality and quality (HFQ) lipids for the preparation of ligand-targeted PEGylated liposomes and demonstrated the advantage of using a serine-glycine repeats $(\mathrm{SG})_{5}$ spacer for efficient peptide ligand presentation on the liposomal surface [22]. This technique is simple and versatile because HFQ lipids are post-inserted into the 
liposomes. GRGDS (RGD) peptides are known to be selective ligands toward the $\alpha_{v} \beta_{3}$ integrin that is overexpressed on tumor neovasculature and tumor cells including those derived from melanoma, prostate, breast, and colon cancers $[23,24]$. We developed HFQ lipids containing the GRGDS (RGD) peptide (RGD-(SG)5-lipid) and succeeded in the more efficient delivery of RGD-(SG)5/PEGylated liposomes to a colon tumor in mice compared with conventional RGD $\mathrm{PEG}_{2000} / \mathrm{PEGylated} \mathrm{liposomes} \mathrm{[25].} \mathrm{In} \mathrm{this} \mathrm{study,} \mathrm{the} \mathrm{RGD-(SG)5-lipid} \mathrm{was} \mathrm{inserted} \mathrm{into} \mathrm{the}$ lipid-based $\mathrm{CaCO}_{3}$ nanoparticles to provide them with a targeting capability. Due to their ability to target both endothelial and tumor cells, the RGD moieties on the nanoparticles were expected to enhance the accumulation of nanoparticles in the tumor region of a broad spectrum of cancers and promote their cellular uptake.

Taking the above mentioned studies into account, we achieved the preparation of PEGylated lipid-based protein/drug/ $/ \mathrm{CaCO}_{3}$ nanoparticles (LPDC) via a 'one-step' method. The RGD-(SG)5-lipid was post-inserted into the nanoparticles (RLPDC) after optimization of the ratios of lipids, proteins and $\mathrm{CaCO}_{3}$ to obtain nanoparticles with a sophisticated structure. We expected the nanoparticles to efficiently co-deliver both the protein and drug to tumor cells (Scheme 1). Targeted RLPDC nanoparticles were selectively distributed to the tumor region and promoted the intracellular delivery of the protein and drug. It was noteworthy that the nanoparticles achieved synchronized bio-distribution in mice, which contributed to the inhibition of tumor growth in vivo. Based on our evaluations, the results from this study provide useful information for the simple preparation of sophisticated lipid-based calcium carbonate nanoparticles. 


\section{Methods}

\subsection{Materials and reagents.}

Egg phosphatidylcholine (EPC) and SOD (Cu/Zn type, 40,000 U/mL) were purchased from Wako Pure Chemical Industries (Osaka, Japan). $\mathrm{N}$-(Carbonyl-methoxypolyethylene glycol 2000)-1,2-distearoyl-sn-glycero-3-phosphoethanolamine (DSPE-PEG 2000 ) and 1,2-dioleoyl-3trimethylammonium-propane (DOTAP) chloride was obtained from NOF corporation (Tokyo, Japan). PTX was purchased from Tokyo Chemical Industry Co., Ltd. (Tokyo, Japan). Bovine serum albumin (BSA) was purchased from Sigma-Aldrich (St. Louis, MO, USA). BSAfluorescein isothiocyanate (FITC) was prepared according to a previously published report [26]. The RGD-(SG)5-lipid was synthesized based on a solid phase peptide synthesis method [25]. The other inorganic chemicals were obtained from Nacalai Tesque (Kyoto, Japan). All organic solvents of analytical grade were purchased from Sigma-Aldrich (St. Louis, MO, USA). Water was prepared using a Direct-Q UV system (Merck Millipore, Merck KGaA, Darmstadt, Germany).

\subsection{Cells and animals.}

The colon26 murine colorectal carcinoma cell line was obtained from RIKEN (Tokyo, Japan). The RPMI 1640 cell culture medium was purchased from Wako Pure Chemical Industries (Osaka, Japan).

Male ddY mice (25-27 g) and BALB/c mice (16-19 g) supplied by Japan SLC Inc. (Shizuoka, Japan) were fed a standard laboratory diet and water, and were housed at ambient temperature and humidity in air-conditioned chambers before the experiments. All animal 
experiments were conducted in full compliance with the Guideline for Animal Experimentation at Nagasaki University.

\subsection{Preparation and optimization of RGD-(SG)5-lipid-inserted lipid/protein/drug/CaCO3 nanoparticles.}

The preparation of nanoparticles with both encapsulated protein and drug was achieved by a 'one-step' ethanol injection method. Briefly, $100 \mu \mathrm{L}$ of BSA or SOD water solution (10 $\mathrm{mg} / \mathrm{mL})$ was mixed with $400 \mu \mathrm{L}$ of propylene glycol (PG), $30 \mu \mathrm{L}$ of $\mathrm{Na}_{2} \mathrm{CO}_{3}$ water solution $(0.2$ $\mathrm{M}), 800 \mu \mathrm{L}$ of EPC ethanol solution $(20 \mathrm{mg} / \mathrm{mL}), 160 \mu \mathrm{L}$ of DOTAP ethanol solution (10 $\mathrm{mg} / \mathrm{mL})$, and $40 \mu \mathrm{L}$ of PTX ethanol solution (2.5 mg/mL) or 1,1'-dioctadecyl-3,3,3',3'tetramethylindodicarbocyanine perchlorate (DiD) ethanol solution $(2 \mathrm{mg} / \mathrm{mL})$ in sequence as the ethanol phase. The water phase was prepared by blending $1.4 \mathrm{~mL} 25 \%$ glucose solution, $1.28 \mathrm{~mL}$ DSPE-PEG 2000 water solution $(5 \mathrm{mg} / \mathrm{mL})$, and $60 \mu \mathrm{L} \mathrm{CaCl}_{2}$ water solution $(0.2 \mathrm{M})$ and adjusted with water to a final ethanol phase/water phase ratio of 1:4 (v/v). Both the ethanol phase and water phase were stirred for $15 \mathrm{~min}$ before mixing. The ethanol phase was added to the water phase dropwise with stirring. After $1 \mathrm{~h}$ stirring at room temperature, the solution was subjected to centrifugal ultrafiltration using an Amicon Ultra-15 tube (MWCO $100 \mathrm{kDa}, 4,830 \times g$ for 20 min, Merck Millipore Ltd., Ireland) three times. The alcohols were removed during this process. The suspension was replenished with $5 \%$ glucose to adjust the final volume to $1 \mathrm{~mL}$.

The RGD-modified nanoparticles were prepared via a post-insertion method. After preparation of the above nanoparticles, the RGD-(SG) $)_{5}$-lipid (4 mg/mL in $5 \%$ glucose) was added dropwise to the nanoparticle suspension in a $60^{\circ} \mathrm{C}$ water bath at a weight ratio of EPC to RGD-(SG)5-lipid of 12.5:1. The mixture was further incubated for $1 \mathrm{~h}$, and the RGD-modified 
nanoparticles were condensed using a centrifugal ultrafiltration tube in a similar fashion as described above.

To evaluate the characteristics of the nanoparticles, different protein/drug combinations were encapsulated. For the study of cellular uptake and bio-distribution, lipid/BSAFITC/DiD/CaCO 3 (LBDC) and RGD-(SG)5-lipid/BSA-FITC/DiD/CaCO 3 (RLBDC) combinations were prepared. To investigate the drug release behavior, a RGD-(SG)5-lipid/BSAFITC/PTX/CaCO $3(\mathrm{RLBPC})$ combination was prepared. For the evaluation of antitumor efficacy, lipid/SOD/PTX/CaCO 3 (LSPC) and RGD-(SG)5-lipid/SOD/PTX/CaCO 3 (RLSPC) combinations were prepared.

\subsection{Determination of calcium ion concentration in the nanoparticles}

The lipid/BSA/CaCO 3 (LBC) nanoparticles and the $\mathrm{Ca}^{2+}$ ions indicator Fura 2 (Dojindo, Kumamoto, Japan) were used to determine the encapsulated $\mathrm{Ca}^{2+}$ ions in the nanoparticles. The LBC nanoparticles were centrifuged using an Amicon Ultra-15 tube (MWCO $100 \mathrm{kDa}, 4,830 \times g$ ) for 30 min to separate the free $\mathrm{Ca}^{2+}$ ions from the nanoparticles. For the determination of total $\mathrm{Ca}^{2+}$ ion concentration in the nanoparticles, $10 \mu \mathrm{L}$ of $\mathrm{LBC}$ nanoparticles with $20 \mu \mathrm{L}$ of $0.1 \mathrm{M} \mathrm{HCl}$ solution were mixed and vortexed for $30 \mathrm{~s}$. The mixed solution was sonicated for $10 \mathrm{~min}$ to release the $\mathrm{Ca}^{2+}$ ions from the nanoparticles completely. Then, $0.1 \mathrm{M}$ phosphate buffer ( $\mathrm{pH} 7.4$ ) of 9.92 $\mathrm{mL}$ and Fura 2 of $50 \mu \mathrm{L}$ were added to the mixture in sequence (the final volume, $10 \mathrm{~mL}$ ). This solution was vortexed for $30 \mathrm{~s}$ and incubated for $15 \mathrm{~min}$ at room temperature to guarantee the combination between $\mathrm{Ca}^{2+}$ ions and Fura 2. For the determination of free $\mathrm{Ca}^{2+}$ ion concentration, $200 \mu \mathrm{L}$ filtrate was used. According to the protocol, the fluorescence of each sample was measured 
at Ex/Em of 340/510 and 380/510, respectively. The concentration of $\mathrm{Ca}^{2+}$ ions were calculated as follows:

$$
\left[\mathrm{Ca}^{2+}\right]=P 1 \times \frac{R-P 2}{P 3-R}
$$

where $\mathrm{R}$ is the ratio of fluorescent intensity $(\mathrm{F}(340) / \mathrm{F}(380))$ of the sample, $\mathrm{P} 1$ is the correction factor including dissociation constant, minimum and maximum fluorescence, $\mathrm{P} 2$ and P3 are the ratio of fluorescent intensities for minimum (calcium-free) and maximum conditions (excess calcium), respectively. P1, P2 and P3 were determined by curve fitting using the values of calcium chloride solutions ( 1 to $40 \mu \mathrm{M})$ as standard.

\subsection{Diameter, $\zeta$ potential and morphology of the nanoparticles.}

A Zetasizer Nano ZS instrument (Malvern, UK) was used to detect the diameter, polydispersity index (PDI) and $\zeta$ potential of the prepared nanoparticles. All nanoparticles were diluted 4 fold with $5 \%$ glucose before analysis. The $\mathrm{pH}$ sensitivity of the nanoparticles was investigated by examining the particle size detection. The LBDC combination was diluted 4 fold with 0.01 M pH 7.4 HEPES buffer or 0.01 M pH 5.5 MES buffer and incubated for $3 \mathrm{~h}$ before detection.

The transmission electron microscopy (TEM) study of the nanoparticles was achieved using a negative staining method. Samples were absorbed to formvar film-coated copper grids and stained with a $2 \%$ phosphotungstic acid solution $(\mathrm{pH} 7.0)$ for $30 \mathrm{~s}$. The grids were observed using a transmission electron microscope (JEM-1400Plus; JEOL Ltd., Tokyo, Japan) at an acceleration voltage of $100 \mathrm{kV}$. Digital images were taken with a CCD camera (EM14830RUBY2; JEOL Ltd., Tokyo, Japan). 


\subsection{SOD activity under the nanoparticle processing conditions.}

The activity of SOD is highly dependent on its structural complexity, making it difficult to formulate the enzyme into nanoparticles. Thus, it is necessary to independently evaluate the effect of the solution components, solvents and processing conditions on the activity of SOD and thus, a SOD stock solution of $400 \mathrm{U} / \mathrm{mL}$ in water was prepared. The SOD solution and the other components were added to a $1.5 \mathrm{~mL}$ microtube and incubated under various conditions (Fig. S1). After incubation for a defined time, the activity of SOD was detected using a SOD Assay Kit (Dojindo, Kumamoto, Japan). The absorbance was measured at $450 \mathrm{~nm}$ using a microplate photometer (Multiskan ${ }^{\mathrm{TM}} \mathrm{FC}$, Thermo Fisher Scientific). The activity of SOD alone in solution at $4^{\circ} \mathrm{C}$ (NO.1 sample) was set as $100 \%$ and the activity of each sample was expressed as a normalized value using sample NO.1 as a control.

\subsection{Drug content and encapsulation efficiency.}

The encapsulated PTX and SOD were separately evaluated using high performance liquid chromatography (HPLC) with a UV detector (SPD-10A, Shimadzu, Kyoto, Japan) and a SOD Assay Kit (Dojindo, Kumamoto, Japan). For the determination of PTX, $20 \mu \mathrm{L}$ of the nanoparticles were added to $980 \mu \mathrm{L}$ methanol and sonicated for $15 \mathrm{~min}$ and then the solution was analyzed at $\lambda=230 \mathrm{~nm}$ using a mobile phase of water to acetonitrile at 40:60 (v/v). The content of SOD was determined from its enzymatic activity. Briefly, $20 \mu \mathrm{L}$ of the nanoparticles were added to $980 \mu \mathrm{L} 0.01 \mathrm{M} \mathrm{pH} 5.5$ MES buffer and incubated in a $37^{\circ} \mathrm{C}$ water bath for $10 \mathrm{~min}$. After a 10 fold dilution using the dilution buffer from the detection kit, the absorbance was measured at $450 \mathrm{~nm}$. 
The quantitation of BSA-FITC and DiD (Thermo Fisher Scientific) was achieved using a fluorescence spectrometer (RF-6000, Shimadzu, Kyoto, Japan). Twenty microliters of the nanoparticles were added to $980 \mu \mathrm{L}$ methanol and sonicated for $15 \mathrm{~min}$. For the detection of BSA-FITC, the solution was diluted 10 fold using $0.1 \mathrm{M} \mathrm{pH} 9.0$ sodium carbonate buffer. The ethanol was used to dilute the DiD 10 fold before detection. The excitation (Ex)/emission (Em) wavelengths for BSA-FITC and DiD were 494/524 nm and 644/670 nm, respectively. The encapsulation efficiency (EE) was calculated in accordance with the following equation:

$$
\mathrm{EE}\left(\text { wt. \%) }=\frac{\text { Weight }_{\text {loaded }}}{\text { Weight }_{\text {feeded }}} \times 100\right.
$$

\section{$2.8 \mathrm{pH}$-sensitive drug release.}

RLBPC was prepared for the release study. The drug release behavior of BSA-FITC and PTX was monitored using a centrifugal ultrafiltration method and a membrane dialysis technique, respectively. The physiological environment and endosomal/lysosomal microenvironment were simulated using $0.01 \mathrm{M} \mathrm{pH}$ 7.4 HEPES buffer and $0.01 \mathrm{M} \mathrm{pH} 5.5 \mathrm{MES}$ buffer, respectively. An aliquot of $0.1 \%$ Tween 80 was added to both media for the solubilization of PTX. For the detection of BSA-FITC, $200 \mu \mathrm{L}$ of RLBPC was added directly to $9.8 \mathrm{~mL}$ media. In a shaking water bath at $37^{\circ} \mathrm{C}, 1 \mathrm{~mL}$ of solution was added to an ultrafiltration tube (MWCO $100 \mathrm{kDa}$ ) at certain intervals and centrifuged at $4,830 \times \mathrm{g}$ for $5 \mathrm{~min}$. The flow-through solution was diluted 5 fold with $0.1 \mathrm{M} \mathrm{pH} 9.0$ sodium carbonate buffer and its fluorescence was measured using a fluorescence spectrometer. For the detection of PTX, $200 \mu \mathrm{L}$ of RLBPC was placed into a dialysis bag (MWCO, $12 \mathrm{kDa}$ ) and exposed to $10 \mathrm{~mL}$ media. In a shaking water bath at $37^{\circ} \mathrm{C}$, $100 \mu \mathrm{L}$ of medium was withdrawn at appropriate time intervals, and the same amount of fresh medium was replenished. The amount of PTX was determined using HPLC. 


\subsection{In vitro intracellular disposition and cellular association.}

Colon26 cells were cultured in RPMI 1640 including 10\% fetal bovine serum (FBS), 100 $\mathrm{U} / \mathrm{mL}$ penicillin and $100 \mu \mathrm{g} / \mathrm{mL}$ streptomycin at $37^{\circ} \mathrm{C}, 5 \% \mathrm{CO}_{2}$ and $90 \%$ relative humidity. The cellular uptake was observed using confocal microscopy (LSM710, Carl Zeiss Microimaging $\mathrm{GmbH}$, Jena, Germany). Briefly, the cells were seeded in glass dishes at a density of $1 \times 10^{5}$ cells/dish and pre-incubated for $24 \mathrm{~h}$. Then, BSA-FITC + DiD, LBDC and RLBDC (final concentration of $14 \mathrm{nM}$ of BSA-FITC and $0.88 \mathrm{nM}$ of DiD) in RPMI 1640 medium (with FBS) were incubated with the cells at $37^{\circ} \mathrm{C}$. After $3 \mathrm{~h}$ incubation, the cells were washed with phosphate-buffered saline (PBS). LysoTracker ${ }^{\circledR}$ Red (Thermo Fisher Scientific) in RPMI 1640 medium $(100 \mathrm{nM})$ was added. After 10 min incubation, the cells were washed with PBS, fixed with 4\% paraformaldehyde in PBS for 15 min, and washed again. DAPI (Sigma-Aldrich) in RPMI 1640 medium $(5 \mu \mathrm{g} / \mathrm{mL})$ was added and incubated for 10 min before washing with PBS. Two drops of Slow Fade Diamond $₫$ (Thermo Fisher Scientific) were added and the samples were subjected to confocal microscopy.

For the quantitation of the cellular association of DiD, a fluorescence-activated flow cytometer (LSRfortessa X-20, Becton Dickinson, USA) was used to detect the fluorescence. To study the mechanism of cellular association, RGD-modified liposomes (RLipo) were prepared in accordance with a previous report [25]. The cells were seeded in a 24-well plate at a density of $1 \times 10^{5}$ cells/well and pre-incubated for $24 \mathrm{~h}$. For the control group, RLBDC (final concentration of $14 \mathrm{nM}$ of BSA-FITC and $0.88 \mathrm{nM}$ of DiD) in RPMI 1640 medium (with FBS) were incubated with the cells for $3 \mathrm{~h}$. The excess amount of Rlipo (20 times the molar ratio in terms of the RGD(SG)5-lipid inserted in the RLBDC) were pre-incubated with the cells for 30 min, and then co- 
incubated with RLBDC at the same concentration of the control group for another $3 \mathrm{~h}$. The cells were washed with PBS, trypsinized and collected, then detected after resuspension in $0.5 \mathrm{~mL}$ of PBS.

\subsection{In vitro cytotoxicity.}

The cytotoxicities of the nanoparticles and blank carrier lipid/ $\mathrm{CaCO}_{3}$ (LC) and RGD(SG)5-lipid/ $\mathrm{CaCO}_{3}$ (RLC) toward Colon26 cells were evaluated by the WST-8 assay (cell counting kit-8, Dojindo, Kumamoto, Japan). The cells were seeded in 96-well plates at a density of $1 \times 10^{4}$ cells/well. After $12 \mathrm{~h}$ incubation, free SOD, PTX, SOD + PTX, LSPC and RLSPC at various concentrations were added to the wells. After $48 \mathrm{~h}$ incubation, the cells were washed with PBS. Then, $10 \mu \mathrm{L}$ of WST-8 in $100 \mu \mathrm{L}$ RMPI 1640 was added to each well and incubated for another $1 \mathrm{~h}$. The absorbance was measured at $450 \mathrm{~nm}$ using a microplate photometer. Blank wells and untreated cells served as negative and positive controls, respectively.

\subsection{Determination of nanoparticle stability in FBS solution.}

The LBDC and RLBDC were added to a PBS solution containing 40\% (v/v) FBS and incubated in a $37^{\circ} \mathrm{C}$ water bath. At defined time intervals, the samples were collected and subjected to centrifugal ultrafiltration $(\mathrm{MWCO} 100 \mathrm{kDa}$ ) at 4,830 $\times \mathrm{g}$ for $10 \mathrm{~min}$. The solution of the inner tube was adjusted to $1 \mathrm{~mL}$ with $5 \%$ glucose. The fluorescence of BSA-FITC and DiD were detected according to the method in Section 2.6 (Drug content and encapsulation efficiency).

\subsection{Establishment of the tumor xenograft model.}


Male BALB/c mice were used to establish the tumor xenograft model. Colon26 cells $(1 \times$ $10^{6}$ cells) were subcutaneously injected into the dorsal side on the back of the mice. The tumor volume was measured by length $(\mathrm{L})$ and width $(\mathrm{W})$ with a vernier caliper. The tumor volume (V) was calculated using the following equation:

$$
\mathrm{V}=\frac{1}{2} \times L \times W^{2}
$$

\subsection{In vivo bio-distribution of the nanoparticles.}

The study was carried out on both the normal ddY mice and colon tumor xenograft $\mathrm{BALB} / \mathrm{c}$ mice. For the normal mice, free BSA-FITC + DiD and LBDC nanoparticles were intravenously injected via the tail vein of ddY mice at a BSA-FITC dose of $1.92 \mathrm{mg} / \mathrm{kg}$. For the tumor xenograft mice, when the tumor volume grew to $100 \mathrm{~mm}^{3}$, free BSA-FITC + DiD, LBDC and RLBDC were intravenously injected via the tail vein at a BSA-FITC dose of $3.84 \mathrm{mg} / \mathrm{kg}$. At specified time points, the mice were anesthetized using a drug mix (butorphanol, medetomidine and midazolam). Blood was taken from the inferior vena cava and then the heart, liver, spleen, lung, kidney and tumor were harvested and weighed.

Tissue optical clearing solutions were used to measure the intensity of fluorescence. For the detection of FITC-BSA, SeeDBp $(80.2 \% \mathrm{w} / \mathrm{v}$ fructose with $0.5 \% \alpha$-thioglycerol in PBS, $\mathrm{pH}$ 8.5 adjusted with $1 \mathrm{M} \mathrm{NaOH}$ ) [27] was employed. Briefly, organs were homogenized with PBS at $3 \mu \mathrm{L} / \mu \mathrm{g}$ for the liver and $6 \mu \mathrm{L} / \mu \mathrm{g}$ for the other organs. Blood was centrifuged at $1,500 \times g$ for 15 min to recover the plasma. For the detection of BSA-FITC, $100 \mu \mathrm{L}$ homogenate and $50 \mu \mathrm{L}$ plasma were mixed with $10 \mu \mathrm{L} 5 \%$ glucose and incubated at $37^{\circ} \mathrm{C}$ for $30 \mathrm{~min}$. Then the sample was mixed with the SeeDBp solution (up to $500 \mu \mathrm{L}$ ) and vortexed for $30 \mathrm{~s}$. For the detection of DiD, $100 \mu \mathrm{L}$ homogenate solution and $20 \mu \mathrm{L}$ plasma were mixed with $10 \mu \mathrm{L} 5 \%$ glucose and 
incubated at $37^{\circ} \mathrm{C}$ for $30 \mathrm{~min}$. Then the sample was mixed with $8 \mathrm{M}$ urea/methanol (3:2) (up to $500 \mu \mathrm{L}$ ) and vortexed for $30 \mathrm{~s}$. The final solutions were detected using a fluorescence spectrometer. For the detection of BSA-FITC and DiD, the Ex/Em wavelengths were 494/524 $\mathrm{nm}$ and $644 / 670 \mathrm{~nm}$, respectively. Standard curves of BSA-FITC and DiD were separately prepared using blank organ homogenates and plasma spiked with BSA-FITC and DiD.

\subsection{In vivo inhibition of tumor growth.}

Tumor-bearing mice with a tumor volume around $100 \mathrm{~mm}^{3}$ were divided into three groups (vehicle, free PTX + SOD solution, and RLSPC nanoparticle groups, $n=6$ ). Free PTX + SOD solution and RLSPC (at an equivalent dose of $0.5 \mathrm{mg} / \mathrm{kg}$ PTX and 13,000 U/kg SOD) were intravenously injected via the tail vein every other day for five times. Glucose solution (5\%) was injected using the same volume as the control. The tumor size and body weight of the mice in each group were recorded and the mice were euthanized by $\mathrm{CO}_{2}$ inhalation when the tumor volume $>3000 \mathrm{~mm}^{3}$. The tumor volume and body weight curves were plotted for time points up to 20 days post treatment. The survival rate curve was calculated using data from mice prior to death or before the tumor volume reached $>3000 \mathrm{~mm}^{3}$. Endpoint for the additionally performed experiments (the effect of RGD-modification, Fig. S5) was set to $2000 \mathrm{~mm}^{3}$ due to the consideration of animal welfare.

\subsection{Statistical analysis.}

The results are represented as the mean \pm standard deviation (SD) in vitro and mean \pm standard error (SE) in vivo of at least three independent experiments. Significant differences were identified using the Student's t-test and one-way ANOVA followed by Bonferroni's post 
hoc test. For survival analysis in the tumor xenograft mice, the Kaplan-Meier method was utilized. To analyze the differences among the survival curves, a log rank test was performed. Subsequent pairwise multiple comparisons were performed by the Holm-Sidak method. A $P$ value of less than 0.05 was statistically significant.

\section{Results and Discussion}

\subsection{Preparation and characterization of nanoparticles}

'One-step' preparation of the PEGylated nanoparticles encapsulating both a protein and a drug is the most attractive advantage of our co-delivery system. LBDC was used for visualization and quantitation and LSPC was used for cytotoxicity evaluation both in vitro and in vivo. In accordance with the results from our previous study of nanocarriers for combination therapies [21], an ethanol injection method was applied to formulate the nanoparticles (Fig. 1A). However, it was challenging to optimize the multiple prescription components with different charge properties and hydrophilicity/lipophilicity to achieve successful preparation of the nanoparticles using a 'one step' formulation. The weight ratio of neutral lipid to positive lipid and lipid to protein, the concentration of $\mathrm{CaCO}_{3}$ and the order of addition were all taken into consideration during the development of the nanoparticles. Based on the size, PDI, $\zeta$-potential and drug encapsulation, the prescription was optimized. The stability of the nanoparticle skeleton was dependent on the EPC to protein weight ratio, which was set to 8:1. The EPC to DOTAP weight ratio was adjusted by balancing the hydrophobic and electrostatic interactions among lipids and proteins as they influence the formation of the nanoparticles. At an EPC/DOTAP weight ratio of 10:1, both the characteristics and drug encapsulation properties of the nanoparticles were optimal. Although a high concentration of $\mathrm{CaCO}_{3}$ was desirable, it affected 
the stability of the nanoparticles. The total and free $\mathrm{Ca}^{2+}$ ion concentrations in the $\mathrm{LBC}$ formulation were $5.04 \pm 0.57 \mathrm{mM}$ and $0.48 \pm 0.05 \mathrm{mM}$, respectively. So, $90.5 \%$ of $\mathrm{Ca}^{2+}$ ions were encapsulated in the nanoparticles, indicating the formation of $\mathrm{CaCO}_{3}$. The theoretical total concentration of $\mathrm{Ca}^{2+}$ ions was $6 \mathrm{mM}$. Thus, $16 \%$ of the $\mathrm{Ca}^{2+}$ ions were lost during the preparation of the nanoparticles, especially during the removal of alcohols by centrifugal ultrafiltration. The final nanoparticles were observed using TEM (Fig. 1B) and characterized (Fig. 1C, D). A sophisticated spherical nanoparticle was observed with a diameter of approximately $130 \mathrm{~nm}$ by TEM, a value that corresponded to the measurements from dynamic light scattering (Fig. 1C). The $6.5 \mathrm{~nm}$ width of the outside layer on the periphery of nanoparticle indicated a lipid bilayer (Fig. 1B). Insertion of the RGD-(SG)5-lipid targeting moiety generated slightly condensed nanoparticles and charge reversal was observed after insertion for both RLBDC/LBDC and RLSPC/LSPC (Fig. 1D), indicating the successful insertion of the RGD(SG)5-lipid with a net positive charge.

During the preparation, the protein was added to the ethanol phase. In general, proteins precipitate in ethanol and lose their activity. Here, we found the utilization of PG at a weight ratio of PG to protein of 400:1 played a key role as a co-solvent and helped the protein to become stably solubilized in the ethanol phase. Although the solubility of $\mathrm{CaCl}_{2}$ in ethanol contributed to the successful formation of our previous LPCCD nanoparticles (lipid/polyacrylic $\mathrm{acid} / \mathrm{CaCO}_{3} /$ curcumin/doxorubicin) [21], the precipitation of proteins was unfortunately observed in the presence of $\mathrm{CaCl}_{2}$. Interestingly, the addition of $\mathrm{Na}_{2} \mathrm{CO}_{3}$ to the ethanol phase improved the solubility of the proteins. Thus, the order of $\mathrm{CaCl}_{2}$ and $\mathrm{Na}_{2} \mathrm{CO}_{3}$ addition was successfully switched in this study (molar ratio of $\mathrm{Ca}^{2+}: \mathrm{CO}_{3}{ }^{2-}=2: 1$ ) and thus, the order of addition in the ethanol phase was concluded to impact the compatibility of the components. The 
interactions between the PG and proteins prior to mixing with EPC prevented the precipitation of proteins, which was induced by the promoted intramolecular and intermolecular hydrophobic interactions. The increased $\mathrm{pH}$ resulting from the addition of $\mathrm{Na}_{2} \mathrm{CO}_{3}$ enhanced the electrostatic interactions between the DOTAP and the proteins. Additionally, the high concentration of EPC added prior to DOTAP interacted with the proteins via hydrophobic interactions, limiting the potential co-precipitation of DOTAP and the proteins induced by electrostatic interactions. Furthermore, preservation of SOD enzymatic activity was tested to determine the feasibility of this preparation method. It was demonstrated that SOD possessed normalized activity in a range of 85 to $110 \%$ under various preparation conditions (Fig. S1). Therefore, the high temperature $\left(60^{\circ} \mathrm{C}\right)$ and pre-mixing in the ethanol phase during the preparation of the nanoparticles did not affect the SOD enzymatic activity. The BSA-FITC/DiD and SOD/PTX combinations showed different encapsulation efficiencies in the nanoparticles, while no obvious difference was observed in the encapsulation after RGD-(SG) 5 -lipid insertion into the nanoparticles (Fig. S2). The small molecules DiD and PTX have similar content and encapsulation efficiencies in the nanoparticles, whereas twice the encapsulation efficiency for BSA (about 60\%) was detected with respect to that of SOD. Taking isoelectric points of BSA $(\mathrm{pI}=6)$ and $\mathrm{SOD}(\mathrm{Cu} / \mathrm{Zn}$ Type, $\mathrm{pI}$ $=4.95$ ) into consideration, the strengths of electrostatic interactions of BSA and SOD with cationic components DOTAP and $\mathrm{Ca}^{2+}$ ions might be similar because both proteins should possess anionic charge at neutral or alkaline $\mathrm{pH}$ during nanoparticle formation. So, the different encapsulation efficiencies might be attributed to the differences in the hydrophobic interactions and/or the molecular weights of BSA $(66.5 \mathrm{kDa})$ and $\mathrm{SOD}(\mathrm{Cu} / \mathrm{Zn}$ Type, $16.3 \mathrm{kDa})$, which may affect the interactions of proteins with lipids and $\mathrm{CaCO}_{3}$. 


\subsection{Verification of $\mathrm{pH}$ sensitivity}

The $\mathrm{pH}$ sensitivity of the nanoparticles was verified by the size variation and release behavior of cargos (Fig. 2). LBDC showed an obvious size enlargement from physiological conditions ( $\mathrm{pH}$ 7.4) to an acidic environment ( $\mathrm{pH} 5.5)$ with slight changes to the PDI and $\zeta$ potential (Fig. 2A). We hypothesized that the nanoparticles were formed on the basis of electrostatic and hydrophobic interactions. In the acidic environment, the disruption of $\mathrm{CaCO}_{3}$ might break the balance of electrostatic interactions among the protein/DOTAP/Ca ${ }^{2+} / \mathrm{CO}_{3}{ }^{2-}$ mixture. Decreased electrostatic attractions and increased repulsions likely led to the partial dissociation of the nanoparticles, while the remaining hydrophobic interactions preserved the morphology of the nanoparticles to some extent. Therefore, this suggested the LBDC might swell as the $\mathrm{pH}$ decreased, however, the integrity of the nanoparticles was maintained. The release behavior of the cargos from the nanoparticles further confirmed their $\mathrm{pH}$ sensitivity (Fig. 2B, C). BSA-FITC showed a robust $\mathrm{pH}$-sensitive release pattern with a sharp release during the initial $1 \mathrm{~h}$ reaching $40 \%$ of the total amount at $\mathrm{pH} 5.5$ and around $80 \%$ cumulative release at 24 $\mathrm{h}$. The decreased release rate of the protein after $1 \mathrm{~h}$ in both media might be attributed to the remaining hydrophobic interaction and/or electrostatic interaction between BSA-FITC and the lipids. The PTX release in $\mathrm{pH} 5.5$ medium was slightly higher than that in $\mathrm{pH} 7.4$ medium. So, PTX in the nanoparticles might interact with $\mathrm{CaCO}_{3}$ in part. The release rate of PTX was slower than that of BSA-FITC. Because PTX is a lipophilic drug, this was probably due to the different degree of interaction with $\mathrm{CaCO}_{3}$.

\subsection{Cellular uptake and intracellular disposition}


Cellular uptake and intracellular trafficking of both BSA-FITC and DiD was analyzed using Colon26 murine colon carcinoma cells. BSA-FITC was observed in only RLBDC-treated cells (Fig. 3A). Because of the high lipophilicity of DiD, the membrane association and cellular uptake of DiD in the free BSA-FITC and DiD combination was more impressive than that of RLBDC (Fig. 3A). The intracellular localization of BSA-FITC and DiD from RLBDC with reference to a lysosome marker are shown in an enlarged figure (Fig. 3B). Entrapped BSA-FITC and intact RLBDC nanoparticles in the lysosome and RLBDC nanoparticles that escaped from the lysosome were partially observed and indicated by their fluorescence signals as specified in Fig. 3. Importantly, the released BSA-FITC and DiD that escaped from the lysosome/endosome and reached the cytosol were clearly observed. The quantitation of RLBDC using flow cytometry confirmed the mechanism of cellular association (Fig. 3C). The mean fluorescence intensity of DiD in RLBDC was 7 times that of the group that was co-incubated with the RGD-(SG)5-lipidinserted liposomes (RLipo), indicating that the high concentration of RLipo competitively inhibited the cellular association of RLBDC. This confirmed that the increased cellular association of RLBDC was mainly attributed to integrin receptor-mediated endocytosis followed by release of the cargos into the cytosolic compartment.

\subsection{Cytotoxicity of the free combination and nanoparticles}

The successful intracellular delivery of the drug/protein combination was further evaluated by determining the cytotoxicity of the SOD/PTX combination. Blank carrier LC and RLC showed no inhibition effect on the colon tumor cells even at the highest concentration of EPC (Fig. 4A). Free SOD showed low cytotoxicity toward tumor cells even at the highest concentration, while free PTX possessed higher cytotoxicity toward the colon tumor cells and 
was concentration dependent (Fig. 4B). The combination of SOD and PTX further improved the inhibition effects. After encapsulation into the nanoparticles, LSPC partly impeded the cytotoxicity of the combination therapy. Although no significant difference between RLSPC and the free SOD + PTX group was observed at the high concentration, RLSPC exhibited the highest cytotoxicity among all preparations, especially at moderate concentrations of SOD $(5 \mathrm{U} / \mathrm{mL})$ and PTX $(0.2 \mu \mathrm{g} / \mathrm{mL})$. It was hypothesized that the long incubation time used in the cytotoxicity study (48 h) facilitated the interactions and cellular uptake of the free drugs. The improved cytotoxicity of the free combination and RLSPC compared with the single drugs verified the synergistic effect of the SOD/PTX combination. The inferior cellular uptake and cytotoxicity of LBDC was attributed to the high percentage of PEGylated lipid (DSPE-PEG 2000) used in the formulation of the nanoparticles. This suggested that the hydration layer constructed by the PEG moiety on the periphery of the nanoparticles might inhibit the interactions with the cells due to steric hindrance [28]. A targeting ligand is necessary to overcome the 'PEG dilemma'. In this study, the inserted RGD-(SG)5-lipid on RLBDC promoted the cellular uptake of BSA-FITC, and the presence of $\mathrm{CaCO}_{3}$ successfully led to endosomal/lysosomal escape and release of the cargos to the cytosol (Fig. 3), resulting in higher cytotoxicity. Thus, insertion of the RGD ligand is a promising strategy to overcome the limitations of PEG and improve the cellular uptake of the nanoparticles.

To check the usefulness of the combination of SOD and PTX, the RGD-(SG)5lipid/SOD/CaCO 3 (RLSC) and RGD-(SG)-lipid/BSA/PTX/CaCO 3 (RLBPC) nanoparticles were prepared and the cytotoxicity was evaluated. The RLSPC possessed superior cytotoxicity to Colon26 cells than RLSC and RLBPC, especially at high concentrations (Fig. S3). 
Although the free combination exhibited similar inhibition effects at the high concentrations in vitro, the use of RLSPC might be more advantageous to overcome the barriers for in vivo delivery. Given that the formation of the nanoparticles was primarily based on the electrostatic and hydrophobic interactions between the proteins and lipids, the high concentration of serum in the circulation might affect the stability of the nanoparticles. Evaluation of the protein and drug leakage from the nanoparticles in the presence of FBS in vitro would provide the foundation for further study in vivo. Both LBDC and RLBDC showed less than $20 \%$ leakage of BSA-FITC and DiD in the presence of 40\% FBS after $12 \mathrm{~h}$ (Fig. S4).

\subsection{In vivo bio-distribution in both normal and tumor xenograft mice}

Subsequently, a bio-distribution study was performed in both normal and tumor xenograft mice. Following intravenous administration of BSA-FITC + DiD solution and LBDC to normal mice, the plasma concentration and tissue accumulation of both BSA-FITC and DiD were determined (Fig. 5). The plasma concentration of BSA-FITC in the LBDC group was slightly higher than that in the free combination at each time point, while the concentration of DiD in the LBDC group was 20 times higher than that in the free combination group. As a consequence, the LBDC significantly increased the circulation time of DiD in vivo (Fig. 5A and B). For combination therapy, the realization of synergistic effects relies on efficient co-delivery of the encapsulated components to the lesioned tissues [29]. Therefore synchronized bio-distribution of cargos is the ultimate goal of nanocarrier delivery. Because the bio-distribution behavior of macromolecules and small molecules are totally different [30], nanocarriers are preferred as a drug delivery method to realize the synchronized bio-distribution of proteins and drugs in vivo. The tissue to plasma (T/P) ratio was used to evaluate the synchronism. In the LBDC group (Fig. 
5C-E), the T/P ratios for both BSA-FITC and DiD were less than unity until at least $6 \mathrm{~h}$ after injection, indicating that LBDC has a good blood circulation property. The T/P ratios of BSAFITC and DiD in the LBDC group were small, whereas the T/P ratios of BSA-FITC and DiD in the free combination group (Fig. 5F-H) were totally different. There were slight differences in the T/P ratios between BSA-FITC and DiD in the LBDC group, possibly indicating the degradation of BSA-FITC and/or the release of DiD from the nanoparticles. At $24 \mathrm{~h}$, the differences between the accumulation of BSA-FITC and DiD in organs in the LBDC group slightly increased, probably due to the released cargos from the nanoparticles. The sufficiently long blood circulation of both BSA and DiD in the LBDC group indicated that the targeting capability of RLBDC was promising.

The targeting capability of RLBDC conferred by the inserted RGD-(SG)5-lipid was verified by the high accumulation of BSA-FITC and DiD in the tumor region of colon tumor xenograft mice after intravenous administration (Fig. 6). The low level of BSA-FITC in the organs might be attributed to the long circulation profile of albumin and the nanoparticles. Tumor accumulation of BSA-FITC in RLBDC group was slightly higher than those in free combination and LBDC groups. High plasma concentrations of DiD were detected in the nanoparticle groups. For the RLBDC group, the accumulation of $\mathrm{DiD}$ in the tumor region was significantly higher than that of the free combination. Tumor accumulation of BSA-FITC in RLBDC was 3.9 times higher than that in LBDC, while the difference in DiD accumulation between RLBDC and LBDC was 1.6 times. So, both enhanced permeability and retention effect [31] and ligand modification should play important roles to deliver the nanoparticles to tumor, especially for the protein delivery. For protein delivery, endosomal escape is important to prevent degradation in lysosomes. So, not only RGD modification, but also $\mathrm{CaCO}_{3}$ may 
contribute to the higher concentration of BSA-FITC in RLBDC group. The significant difference detected between RLBDC and LBDC further demonstrated the promising anticancer efficacy of the RGD-modified nanoparticle delivery system.

\subsection{Evaluation on the inhibition effects of nanoparticles in vivo}

Based on the results of the in vivo bio-distribution studies, the antitumor activities of the free SOD + PTX and RLSPC nanoparticles were evaluated in the colon tumor xenograft mice (Fig. 7). No mice died during the study and all the mice were euthanized when the tumor volume reached more than $3,000 \mathrm{~mm}^{3}$. The free SOD + PTX combination postponed the steep increase in tumor volume as indicated by the delay in the inflection point and slightly prolonged the survival time compared with the control group although no significant difference was detected. Alexandre et al. demonstrated that the addition of SOD further increased the $\mathrm{H}_{2} \mathrm{O}_{2}$ level in PTXtreated tumor cells and enhanced the cytotoxicity in vitro [32]. However, in this study, consecutive treatments of free SOD + PTX exhibited only slight inhibition effects during the initial stage of tumor growth (Fig. 7A). RLSPC obviously outperformed the free combination in terms of its tumor growth inhibition. The tumor volume curve for the RLSPC treatment was nearly flat, showed no remarkable inflection point, and had the smallest tumor volume on the $20^{\text {th }}$ day post treatment. RLSPC also showed the longest survival time analyzed by the KaplanMeier method (Fig. 7C and D). There was no significant difference in body weight among the groups, indicating the low toxicity of RLSPC (Fig. 7B).

To test the necessity of RGD modification, the tumor inhibition effects of LSPC and RLSPC nanoparticles were evaluated (Fig. S5). While the RLSPC nanoparticles exhibited the antitumor activity again, the LSPC nanoparticles did not suppressed the tumor growth. So, RGD 
modification of the nanoparticles were essential for the antitumor activity of the nanoparticles developed in this study.

Overall, the synchronized bio-distribution of the SOD/PTX combination and the targeting capability to the tumor region conferred by the RGD-modified nanoparticles led to the marked antitumor effect with low toxicity.

\section{Conclusion}

We designed novel RGD-modified $\mathrm{pH}$-sensitive nanoparticles using lipids and $\mathrm{CaCO}_{3}$ for efficient intracellular co-delivery of a protein/drug combination to treat tumors. The nanoparticles can be prepared by a 'one-step' ethanol injection method. The self-assembled lipid bilayer conferred the desirable protection of the condensed core in serum, which mimicked in vivo circulating blood. Major destabilization occurred in an acidic environment through the decomposition of $\mathrm{CaCO}_{3}$, which promoted the intracellular protein/drug release. Integrinreceptor targeting via an RGD peptide improved tumor accumulation and cellular uptake in tumor bearing mice. In addition, the nanoparticles possessed sufficient co-delivery ability in vitro and synchronized bio-distribution of protein and drug in vivo. The RGD-modified nanoparticles containing the protein/drug combination achieved promising tumor growth inhibition effects in vivo. Hence, the results from this study provide the foundation for the development of a sophisticated, functionalized and versatile nanoplatform for further advancement of targeted protein/drug co-delivery systems.

Abbreviations: BSA, bovine serum albumin; DDS, drug delivery system; DiD, 1,1'-dioctadecyl3,3,3',3'-tetramethylindodicarbocyanine perchlorate; DOTAP, 1,2-dioleoyl-3- 
trimethylammonium-propane; EE, encapsulation efficiency; Em, emission; EPC, egg phosphatidylcholine; Ex, excitation; FBS, fetal bovine serum; FITC fluorescein isothiocyanate; LBDC, lipid/BSA-FITC/DiD/CaCO 3 ; LBPC, lipid/BSA-FITC/PTX/CaCO $;$ LC, lipid/CaCO LPCCD, lipid/polyacrylic acid/CaCO $3 /$ curcumin/doxorubicin; LPDC, lipid/protein/drug/ $\mathrm{CaCO}_{3}$; LSPC, lipid/SOD/PTX/CaCO 3 ; PBS, phosphate-buffered saline; PDI, polydispersity index; PEG, polyethylene glycol; PG, propylene glycol; PTX, paclitaxel; RGD, arginylglycylaspartic acid; RLBDC, RGD-modified LBDC; RLBPC, RGD-modified lipid/BSA/PTX/CaCO $;$; RLC, RGDmodified LC; RLPDC, RGD-modified LPDC; RLSC, RGD-modified lipid/SOD/CaCO $;$;LSPC, RGD-modified LSPC; ROS, reactive oxygen species; SG, serine-glycine; SOD, superoxide dismutase; TEM, transmission electron microscopy; TRAIL, tumor necrosis factor-related apoptosis-inducing ligand.

\section{Author Contributions}

J.Q.P. and H.M. performed the experiments and analyses. T.S. and S.K. synthesized the RGD(SG)5-lipid. S.F., N.K. and K.N. managed the project.

\section{Additional information}

The authors declare no competing financial interest.

\section{Acknowledgements}

TEM observation was performed by Tokai Electron Microscopy, Inc. (Aichi, Japan). This work was financially supported by MEXT/JSPS KAKENHI grant number JP18K12081, the Takeda Science Foundation and the Basic Foundation of Guizhou Province Department of Science and 
Technology ([2019]1255). We thank Renee Mosi, PhD, from Edanz Group (www.edanzediting.com/ac) for editing a draft of this manuscript.

\section{Appendix A. Supplemental data}

Supplementary data to this article can be found online at https://.

\section{References}

[1] K. de Gaetano Donati, R. Rabagliati, L. Iacoviello, R. Cauda, HIV infection, HAART, and endothelial adhesion molecules: current perspectives, Lancet Infect. Dis. 4 (2004) 213-222.

[2] P. Orjuela, I. González, L. Osorio, Combination therapy as a strategy to prevent antimalarial drug resistance. Biomedica 24 (2004) 423-437.

[3] H.J. Broxterman, N.H. Georgopapadakou, Anticancer therapeutics: "Addictive" targets, multi-targeted drugs, new drug combinations. Drug Resist. Updat. 8 (2005) 183-197.

[4] F. Muggia, Platinum compounds 30 years after the introduction of cisplatin: implications for the treatment of ovarian cancer. Gynecol. Oncol. 112 (2009) 275-281.

[5] H.S. Rugo, Bevacizumab in the treatment of breast cancer: rationale and current data. Oncologist 9 (2004) 43-49.

[6] B. Leader, Q.J. Baca, D.E. Golan, Protein therapeutics: a summary and pharmacological classification. Nat. Rev. Drug Discov. 7 (2008) 21-39.

[7] M. Yu, J. Wu, J. Shi, O.C. Farokhzad, Nanotechnology for protein delivery: Overview and perspectives. J. Control. Release 240 (2016) 24-37.

[8] T. Jiang, W. Sun, Q. Zhu, N.A. Burns, S.A. Khan, R. Mo, et al., Furin-Mediated Sequential Delivery of Anticancer Cytokine and Small-Molecule Drug Shuttled by Graphene. Adv. Mater. 27 (2015) 1021-1028.

[9] C. Monterrubio, S. Paco, N.G. Olaciregui, G. Pascual-Pasto, M. Vila-Ubach, M. CuadradoVilanova, et al., Targeted drug distribution in tumor extracellular fluid of GD2-expressing neuroblastoma patient-derived xenografts using SN-38-loaded nanoparticles conjugated to the monoclonal antibody 3F8. J. Control. Release 255 (2017) 108-119. 
[10] S.A. Shein, I.I. Kuznetsov, T.O. Abakumova, P.S. Chelushkin, P.A. Melnikov, A.A. Korchagina, et al., VEGF-and VEGFR2-Targeted Liposomes for Cisplatin Delivery to Glioma Cells. Mol. Pharm. 13 (2016) 3712-3723.

[11]J.L. Jin, J. Gong, T.J. Yin, Y.J. Lu, J.J. Xia, Y.Y. Xie, et al., PTD4-apoptin protein and dacarbazine show a synergistic antitumor effect on B16-F1 melanoma in vitro and in vivo. Eur. J. Pharmacol. 654 (2011) 17-25.

[12] S.J. Olijslagers, Y.H. Zhang, C. Backendorf, M.H. Noteborn, Additive cytotoxic effect of apoptin and chemotherapeutic agents paclitaxel and etoposide on human tumour cells. Basic Clin. Pharmacol. Toxicol. 100 (2007) 127-131.

[13]Y. Song, X. Xin, X. Zhai, Z. Xia, K. Shen, Sequential combination therapy with flavopiridol and autocatalytic caspase-3 driven by amplified hTERT promoter synergistically suppresses human ovarian carcinoma growth in vitro and in mice. J. Ovarian Res. 7 (2014) 121.

[14] M. Schieber, N.S. Chandel, ROS function in redox signaling and oxidative stress. Curr. Biol. 24 (2014), R453-462.

[15]R.A. Cairns, I.S. Harris, T.W. Mak, Regulation of cancer cell metabolism. Nat. Rev. Cancer $11(2011) 85-95$.

[16]M. Benhar, I. Dalyot, D. Engelberg, A. Levitzki, Enhanced ROS production in oncogenically transformed cells potentiates c-Jun N-terminal kinase and p38 mitogen-activated protein kinase activation and sensitization to genotoxic stress. Mol. Cell. Biol. 21 (2001) 6913-6926.

[17]A. Laurent, C. Nicco, C. Chéreau, C. Goulvestre, J. Alexandre, A. Alves, et al., Controlling tumor growth by modulating endogenous production of reactive oxygen species. Cancer Res. 65 (2005) 948-956.

[18]M. Wang, K. Alberti, S. Sun, C.L. Arellano, Q. Xu, Combinatorially Designed Lipid-like Nanoparticles for Intracellular Delivery of Cytotoxic Protein for Cancer Therapy. Angew. Chem. Int. Ed. 126 (2014) 2937-2942.

[19]Y. Ueno, H. Futagawa, Y. Takagi, A. Ueno, Y. Mizushima, Drug-incorporating calcium carbonate nanoparticles for a new delivery system. J. Control. Release 103 (2005) 93-98.

[20]K.H. Min, H.S. Min, H.J. Lee, D.J. Park, J.Y. Yhee, K. Kim, et al., pH-controlled gasgenerating mineralized nanoparticles: a theranostic agent for ultrasound imaging and therapy of cancers. ACS nano 9 (2015) 134-145. 
[21]J. Peng, S. Fumoto, H. Miyamoto, Y. Chen, N. Kuroda, K. Nishida, One-step formation of lipid-polyacrylic acid-calcium carbonate nanoparticles for co-delivery of doxorubicin and curcumin. J. Drug Target. 25 (2017) 704-714.

[22]T. Suga, Y. Fuchigami, M. Hagimori, S. Kawakami, Ligand peptide-grafted PEGylated liposomes using HER2 targeted peptide-lipid derivatives for targeted delivery in breast cancer cells: The effect of serine-glycine repeated peptides as a spacer. Int. J. Pharm. 521 (2017) 361364.

[23] M. Amin, M. Mansourian, G. Koning, A. Badiee, M. Jaafari, T. Ten Hagen, Development of a novel cyclic RGD peptide for multiple targeting approaches of liposomes to tumor region. J. Control. Release 220 (2015) 308-315.

[24]J. Desgrosellier, D. Cheresh, Integrins in cancer: biological implications and therapeutic opportunities. Nat. Rev. Cancer 10 (2010) 9-22.

[25]T. Suga, N. Kato, M. Hagimori, Y. Fuchigami, N. Kuroda, Y. Kodama, et al., Development of high functionality and quality lipids with RGD peptide ligands: application for PEGylated liposomes and analysis of intratumoral distribution in a murine colon cancer model. Mol. Pharm. 15 (2018) 4481-4490.

[26]E. Harlow, D. Lane, Antibodies: A laboratory manual. Cold Spring Harbor Laboratory 1988, 353-355.

[27]M. Ke, S. Fujimoto, T. Imai, SeeDB: a simple and morphology-preserving optical clearing agent for neuronal circuit reconstruction. Nat. Neurosci. 16 (2013) 1154-1161.

[28] S. Hama, S. Itakura, M. Nakai, K. Nakayama, S. Morimoto, S. Suzuki, et al., Overcoming the polyethylene glycol dilemma via pathological environment-sensitive change of the surface property of nanoparticles for cellular entry. J. Control. Release 206 (2015) 67-74.

[29] S. Guo, C. Lin, Z. Xu, L. Miao, Y. Wang, L. Huang, Co-delivery of cisplatin and rapamycin for enhanced anticancer therapy through synergistic effects and microenvironment modulation. ACS Nano 8 (2014) 4996-5009.

[30]K. Vasquez, C. Casavant, J. Peterson, Quantitative whole body biodistribution of fluorescentlabeled agents by non-invasive tomographic imaging. PLoS One 6 (2011) e20594.

[31]H. Maeda, J. Wu, T. Sawa, Y. Matsumura, K. Hori, Tumor vascular permeability and the EPR effect in macromolecular therapeutics: a review. J. Control. Release 65 (2000) 271-284. 
[32] J. Alexandre, Y. Hu, W. Lu, H. Pelicano, P. Huang, Novel action of paclitaxel against cancer cells: bystander effect mediated by reactive oxygen species. Cancer Res. 67 (2007) 35123517. 
Figures

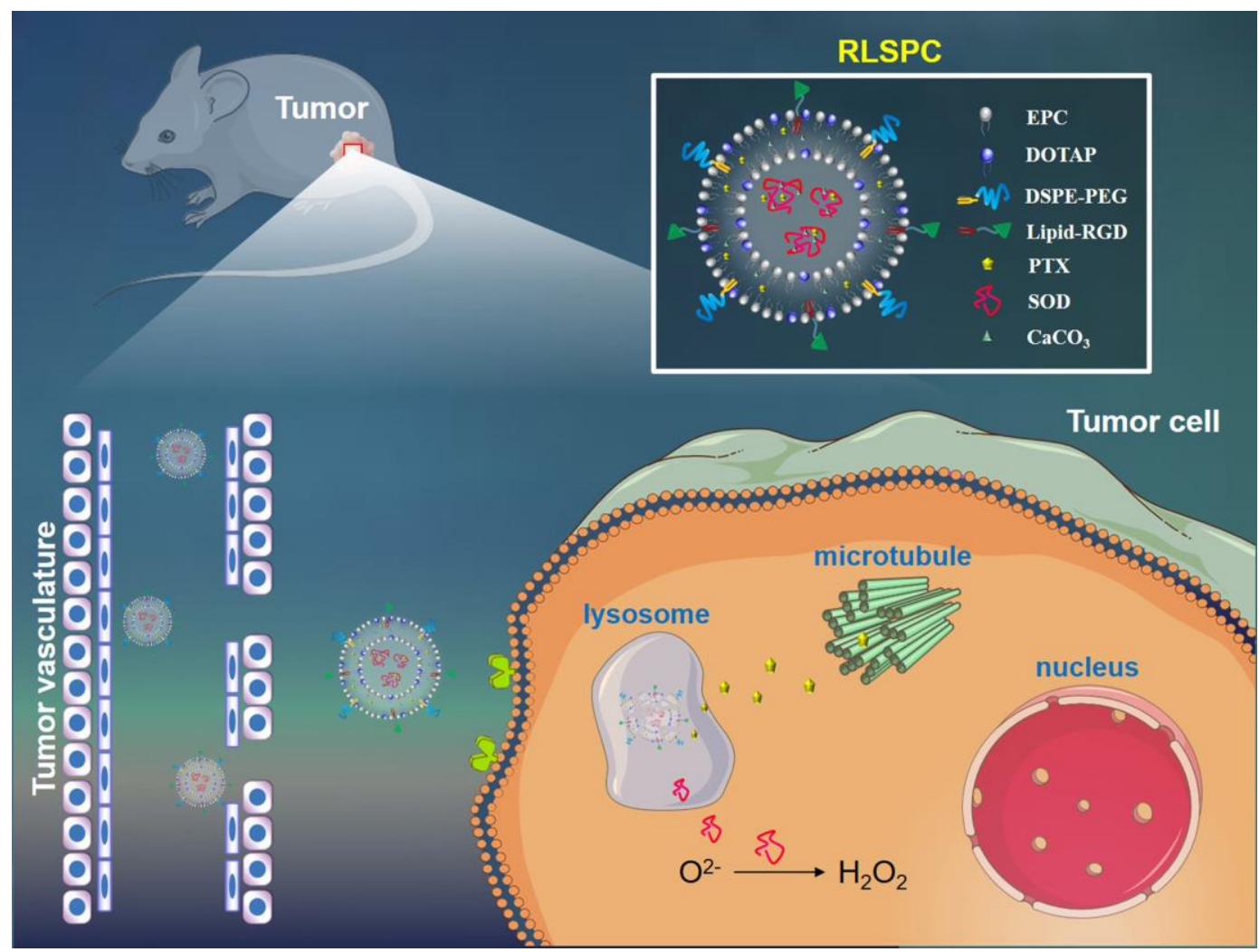

Scheme 1. Schematic illustration of lipid-based $\mathrm{CaCO} 3$ nanoparticles for tumor targeting and $\mathrm{pH}$-sensitive drug release of protein/drug combination therapies. 
A

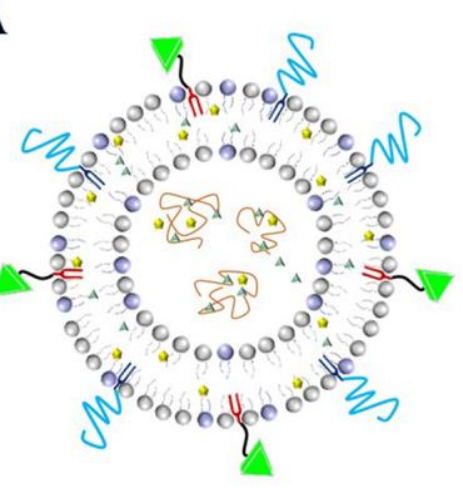

O EPC

○ DOTAP

工W DSPE-PEG

$\sim \sim$ Lipid-RGD

a PTX

\& $\mathrm{SOD}$

${ }_{4} \mathrm{CaCO}_{3}$
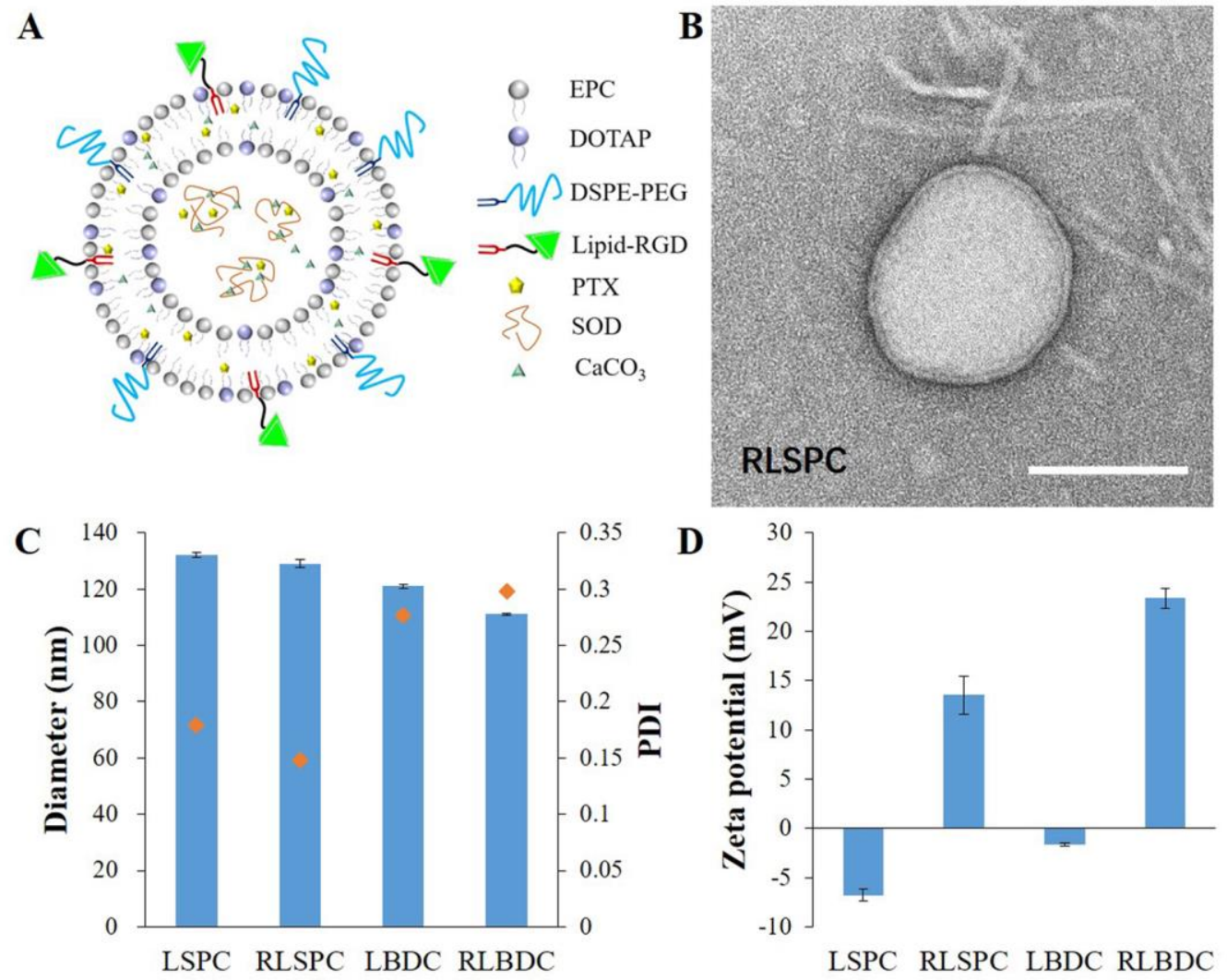

Fig. 1. Properties of the nanoparticles encapsulating a protein/drug combination. (A) Hypothesized structure of RLSPC nanoparticles. (B) Representative TEM image of a RLSPC nanoparticle (scale bar $100 \mathrm{~nm}$ ). (C) Diameter (blue bars) and PDI (orange dots) of the nanoparticles. (D) $\zeta$-potential of the nanoparticles. Each bar represents the mean $\pm \mathrm{SD}$ of at least three experiments. 

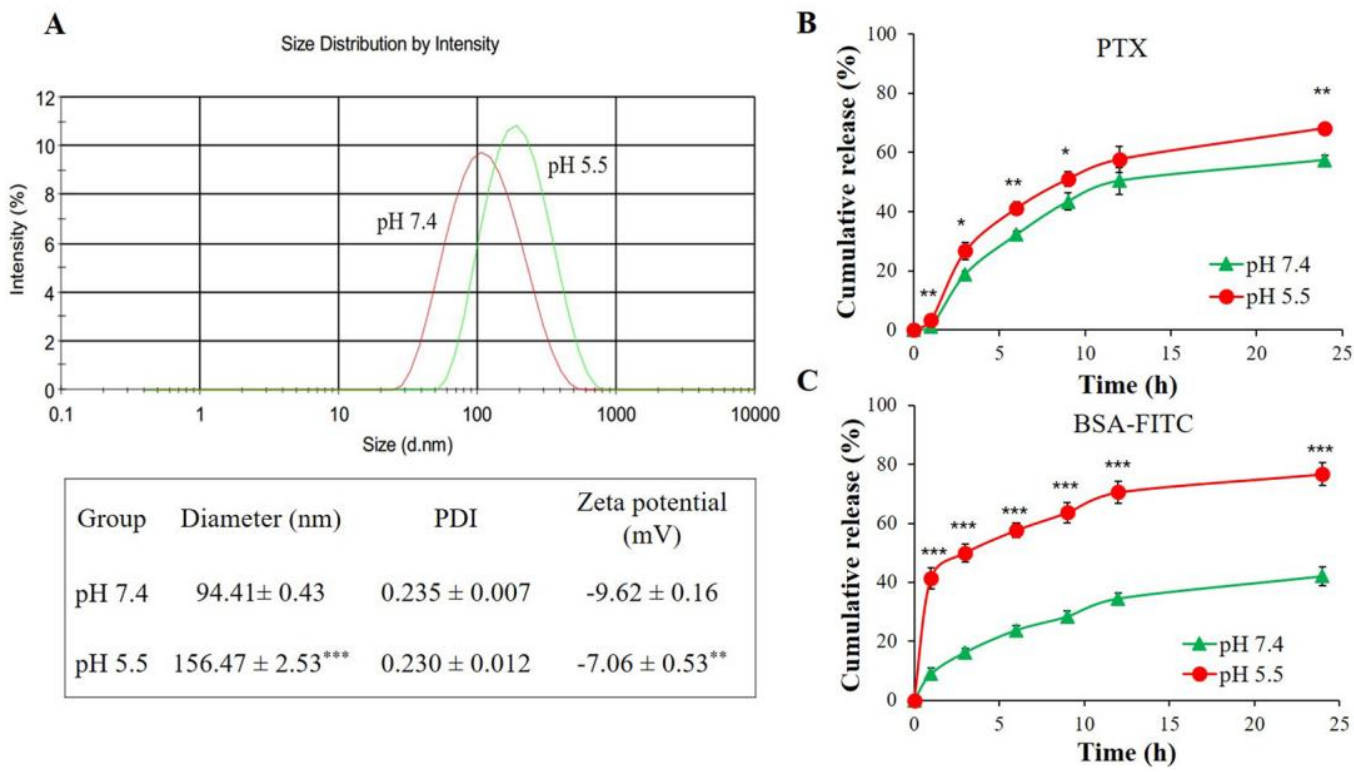

Fig. 2. pH-sensitivity of the nanoparticles. (A) Size variation of LBDC after a $3 \mathrm{~h}$ incubation with media at different $\mathrm{pH}$ levels. Drug release of (B) PTX and (C) BSA-FITC from lipid/BSAFITC/PTX/CaCO3 (LBPC) nanoparticles in 0.01 M pH 7.4 HEPES buffer and 0.01 M pH 5.5 MES buffer. For the detection of PTX, 0.1\% Tween 80 was added to the media. Each symbol represents the mean $\pm \mathrm{SD}$ of at least three experiments. Significant differences from the $\mathrm{pH} 7.4$ group are represented as $* \mathrm{P}<0.05, * * \mathrm{P}<0.01, * * * \mathrm{P}<0.001$. 


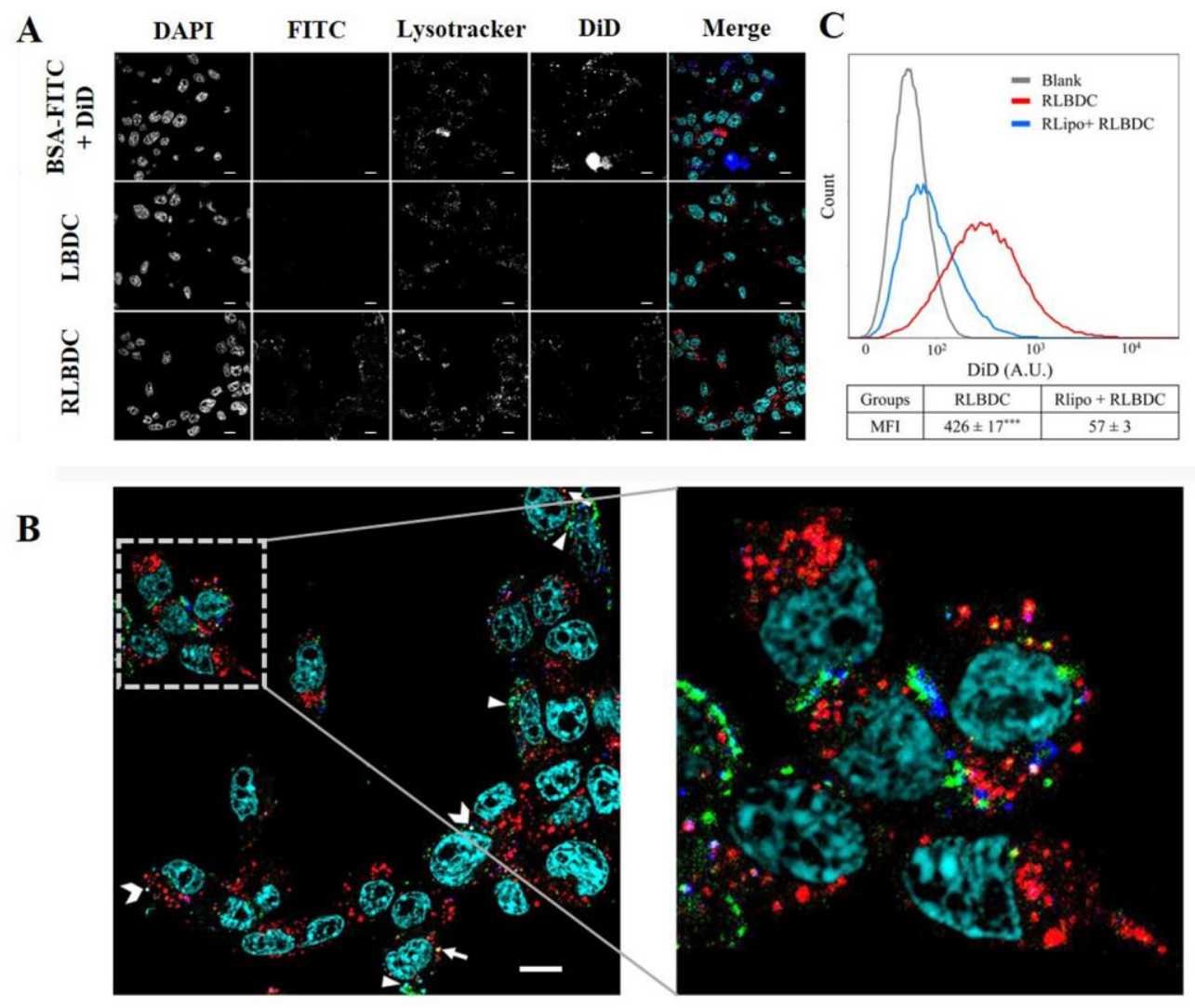

Fig. 3. Intracellular distribution and cellular association of the nanoparticles. (A) Confocal microscopy images of the intracellular distribution of BSA-FITC + DiD, LBDC and RLBDC $3 \mathrm{~h}$ after incubation with the Colon26 tumor cells. Scale bar: $10 \mu \mathrm{m}$. (B) An enlarged and merged image of RLBDC. DAPI (nuclei, cyan), BSA-FITC (green), LysoTracker®Red (red) and DiD (blue). Arrows, V-shaped markers and arrowheads represent BSA-FITC entrapped in endosomal/lysosomal compartments (the yellow spots, co-localization of green and red), nanoparticles entrapped in endosomal/lysosomal compartments (white spots, co-localization of green, blue and red), and nanoparticles that escaped from endosomal/lysosomal compartments (cyan spots, co-localization of green and blue), respectively. Green and blue spots represent released BSA-FITC and DiD in the cytosol, respectively. Scale bar: $10 \mu \mathrm{m}$. (C) Flow cytometry for the cellular association of RLBDC and RLipo + RLBDC in terms of DiD. Mean fluorescent intensities (MFIs) are expressed as the mean \pm SD of three experiments. The MFI of blank cells was subtracted from each value. Significant differences from the RLipo + RLBDC group are represented as $* * * \mathrm{P}<0.001$. 

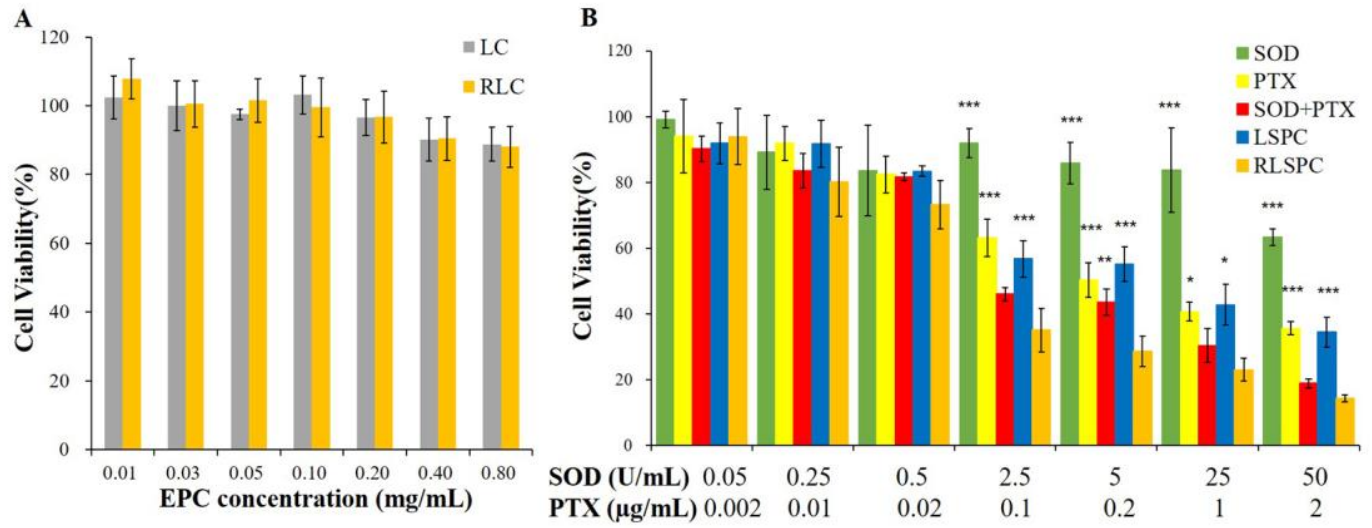

Fig. 4. Cytotoxicity of the nanoparticles. (A) Blank carriers LC and RLC nanoparticles at different concentrations of EPC. (B) Free SOD, PTX, SOD + PTX, LSPC and RLSPC at different concentrations of SOD and PTX. Each bar represents the mean \pm SD of at least three experiments. Significant differences from the RLSPC group are represented as * $\mathrm{P}<0.05, * * \mathrm{P}<$ $0.01, * * * \mathrm{P}<0.001$. 


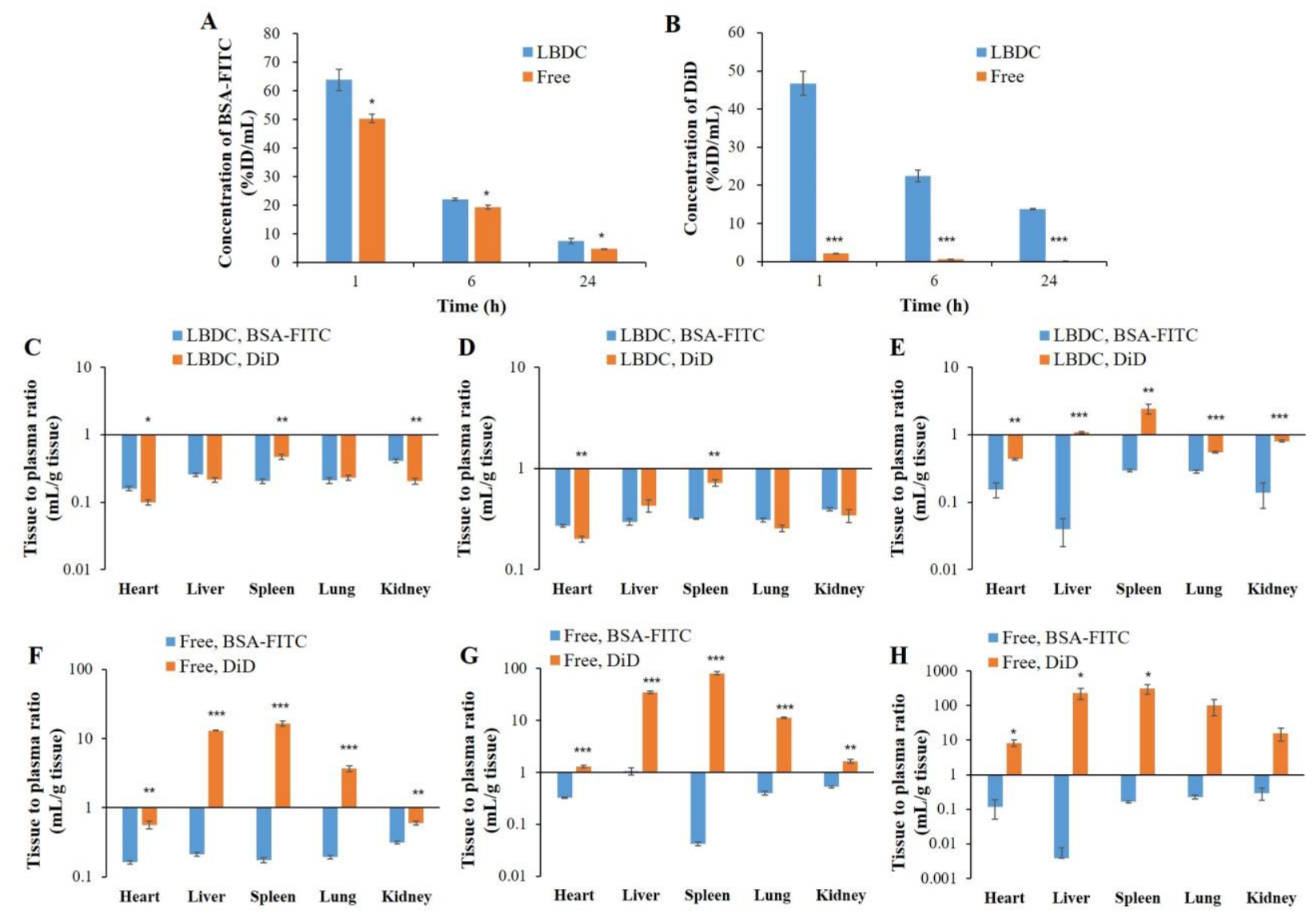

Fig. 5. Synchronized bio-distribution of BSA-FITC and DiD from nanoparticle delivery in mice. Plasma concentration of (A) BSA-FITC and (B) DiD from free combination solutions and LBDC in mice. The T/P ratios for BSA-FITC and DiD from (C-E) LBDC and (F-H) free combinations in the heart, liver, spleen, lung and kidney $1(\mathrm{C}, \mathrm{F}), 6(\mathrm{D}, \mathrm{G})$ and $24 \mathrm{~h}(\mathrm{E}, \mathrm{H})$ after i.v. injection. Each bar represents the mean $\pm \mathrm{SE}$ of at least three experiments. Significant differences from the LBDC group are represented as $* \mathrm{P}<0.05, * * \mathrm{P}<0.01, * * * \mathrm{P}<0.001$. 

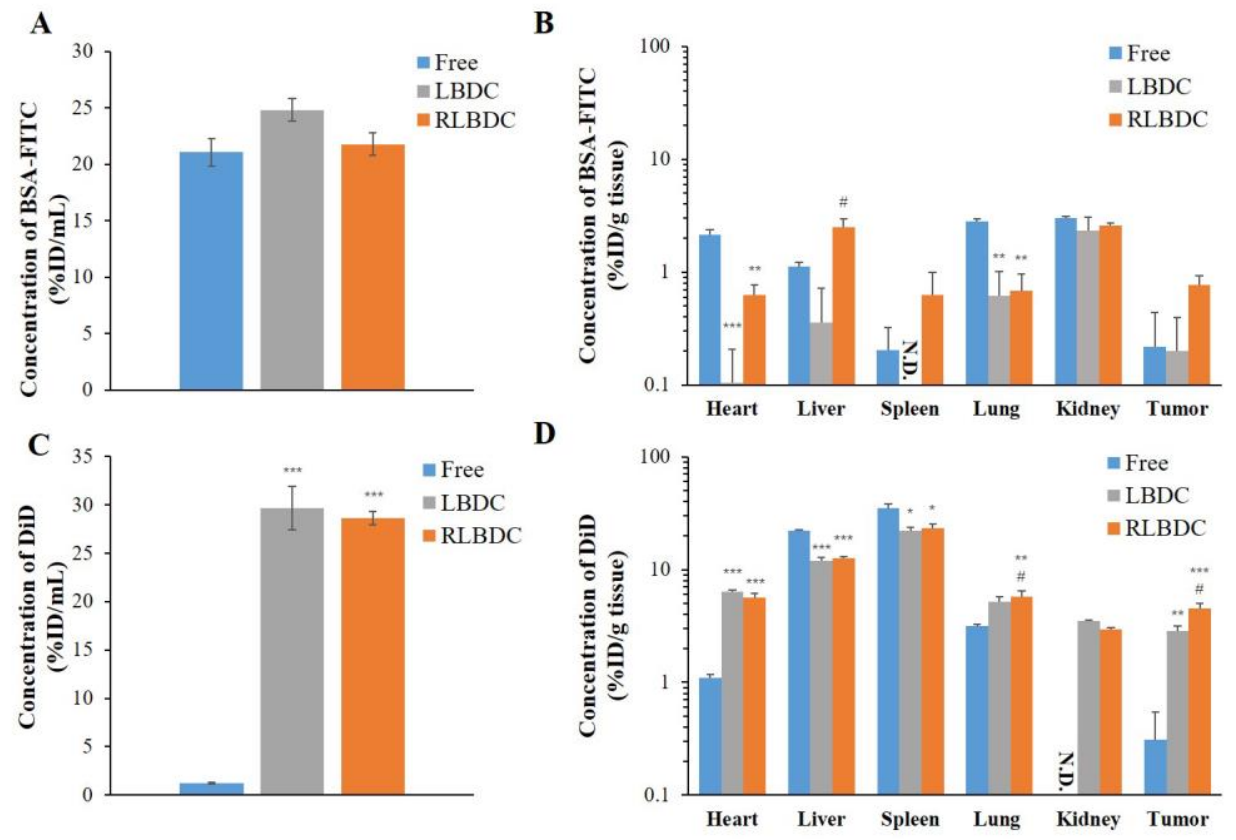

Fig. 6. Bio-distribution of the nanoparticles in colon tumor xenograft mice. Plasma concentration of (A) BSA-FITC and (C) DiD and accumulation of (B) BSA-FITC and (E) DiD in the heart, liver, spleen, lung, kidney and tumor at $6 \mathrm{~h}$ after i.v. injection of the free combination, LBDC and RLBDC nanoparticles. Each bar represents the mean $\pm \mathrm{SE}$ of at least three experiments. Significant differences from the free combination are represented as $* \mathrm{P}<0.05, * * \mathrm{P}<0.01$, *** $\mathrm{P}<0.001$. Significant differences from the LBDC group are represented as $\# \mathrm{P}<0.05$. N.D., not detected. 

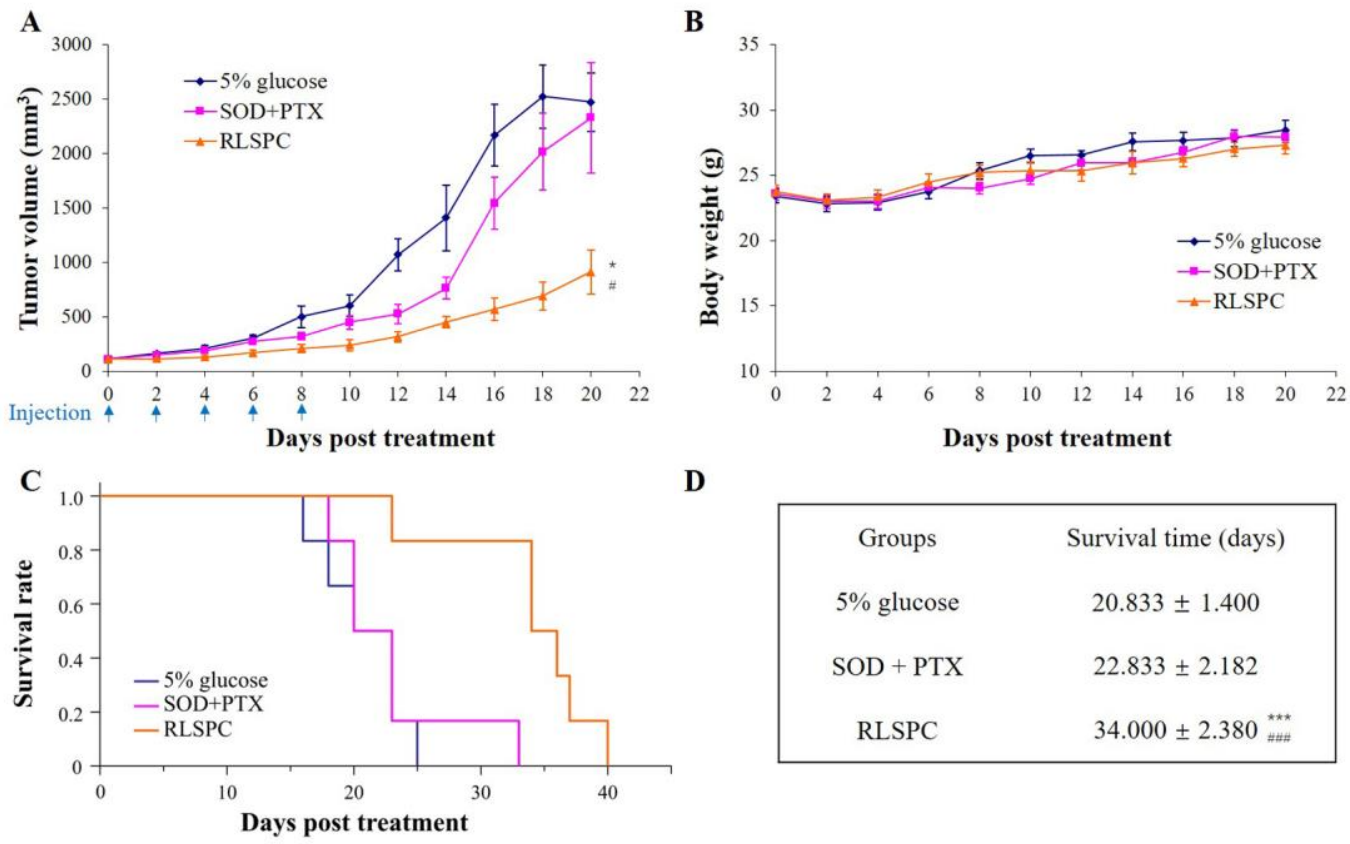

D

\begin{tabular}{|cc|}
\hline Groups & Survival time (days) \\
$5 \%$ glucose & $20.833 \pm 1.400$ \\
SOD + PTX & $22.833 \pm 2.182$ \\
RLSPC & $34.000 \pm 2.380 \ldots$ \\
\hline
\end{tabular}

Fig. 7. In vivo antitumor activity of the nanoparticles in colon tumor xenograft mice. (A) Tumor volume, (B) body weight, (C) survival rate, and (D) mean survival time of mice after consecutive injection of 5\% glucose, free SOD + PTX and RLSPC nanoparticles. Each symbol represents the mean $\pm \mathrm{SE}$ of at least six experiments. Significant differences from the $5 \%$ glucose group are represented as $* \mathrm{P}<0.05, * * * \mathrm{P}<0.001$. Significant differences from the free combination group are represented as \# $\mathrm{P}<0.05$, \#\#\# $\mathrm{P}<0.001$. 